\title{
Application of Platelet-rich Plasma and Tricalcium Phosphate in the Treatment of Comminuted Fractures in Animals
}

\author{
TOMASZ SZPONDER ${ }^{1,2}$, JOANNA WESSELY-SZPONDER ${ }^{3}$, ALEKSANDRA SOBCZYŃSKA-RAK ${ }^{1,2}$, \\ BEATA ŻYLIŃSKA ${ }^{1,2}$, RADOSŁAW P. RADZKI ${ }^{4}$ and IZABELLA POLKOWSKA ${ }^{1,2}$ \\ ${ }^{1}$ Clinic of Animal Surgery, and Departments of ${ }^{2}$ Animal Surgery, ${ }^{3}$ Pathophysiology, and ${ }^{4}$ Animal Physiology, \\ Faculty of Veterinary Medicine, University of Life Sciences, Lublin, Poland
}

\begin{abstract}
Aim: To assess the applicability of $\beta$-tri-calcium phosphate (TCP) and platelet-rich plasma (PRP) in the treatment of comminuted fractures in small animals. Material and Methods: The experimental study was carried out on 16 New Zealand White rabbits. After creating the bone defect and performing tibial osteotomy, TCP implants containing activated PRP were introduced into the fracture and the defect. The fracture was stabilised using external fixators or intramedullary nails. After 12 weeks, the animals were euthanised, and radiological, histological, scanning electron microscopy and peripheral quantitative computed tomography examinations were performed. The analysis also covered the results of fracture treatment in 37 small animals (cats and dogs) in which treatment with TCP containing PRP was used as an alternative to cancellous bone implantation. Results: Correct bone union was observed in the experimental groups, TCP remained visible at the site of the fracture after 12 weeks. In the clinical application in small animals, bone union was observed in over $91 \%$ of treated animals. Conclusion: $\beta-T C P$ and activated PRP may be an effective method of bone union enhancement in the treatment of comminuted fractures in small animals.
\end{abstract}

Comminuted fractures occur in small animals as a result of high-energy trauma and pose a considerable challenge to veterinary practitioners due to the necessity to fill bone the defect as well as possibility of complications. The standard therapeutic procedure entails the use of autologous cancellous

This article is freely accessible online.

Correspondence to: Tomasz Szponder, Department and Clinic of Animal Surgery, Faculty of Veterinary Medicine, University of Life Sciences, Głęboka 30, 20-612 Lublin, Poland. E-mail: tomszpon@op.pl

Key Words: Platelet-rich plasma, comminuted fracture, $\beta$-tricalcium phosphate, bone healing. bone grafts. The graft-harvesting procedure extends the duration of surgery, exacerbates bleeding and pain, and creates a risk of fracture at the collection site. Another restrictive factor is the limited volume of available graft material, particularly in miniature breeds and cats $(1,2)$. One of the alternative methods of supplementing bone loss involves the use of synthetic bone substitute materials as a matrix and platelet-rich plasma (PRP) as the source of growth factors. However, the results of studies conducted on animals to date have been inconclusive. Numerous authors report positive results in experimental studies on the use of $\beta$ tricalcium phosphate (TCP) and PRP gel in the treatment of fractures (3-6), but others report a lack of positive results (7, $8)$. The aim of this study was to develop a research model as close as possible to the actual treatment of comminuted fractures in small animals using TCP and PRP, and subsequently, to apply the obtained results in the treatment of comminuted fractures in small animals.

\section{Materials and Methods}

Experimental study. The performed experimental study was approved by the Second Local Ethics Committee at the University of Life Sciences in Lublin under approval no. 40/2004. The experiment was conducted on a group of 16 male New Zealand White rabbits aged between 9 and 10 months, weighing between 3.5 and $4 \mathrm{~kg}$ (mean body mass $3.7 \mathrm{~kg}$ ). The rabbits were divided into two study groups of 6 animals each in which where different methods of fracture stabilisation would be used, and a control group of four animals. Fractures in group 1 were treated using external fixators and those in group 2 using Kirshner intramedullary nails. In both experimental groups, TCP and PRP were used to enhance bone union. Fractures in the control group were treated using external fixators in two animals and using intramedullary nails in the remaining two rabbits, without any biomaterial implantation. The experiments were conducted at the Department and Clinic of Veterinary Surgery of the University of Life Sciences in Lublin, Poland. The animals were individually caged and fed with LSK complete ration rabbit feed (Agropol Motycz, Poland) with the addition of hay and unlimited access to water. 
Surgery. The rabbits were anaesthetised by way of premedication with a mixture of $2 \mathrm{mg} / \mathrm{kg}$ xylazine (Sedazin, Biowet Puławy, Puławy, Poland) and $15 \mathrm{mg} / \mathrm{kg}$ ketamine (Vetaketam Vet-Agro, Lublin, Poland) i.m., and subsequently by continuous infusion of a mixture of ketamine (Vetaketam) and diazepam (Polfa Warszawa, Poland). In all animals, the surgery was performed on the left tibial bone, medially. After exposing the periosteum at the mid-shaft of the tibia, a drill was used to create a $3 \mathrm{~mm}$ hole, following which an oscillating saw was used to perform osteotomy of the tibia and the fibula. In group 1, the bone fragments were stabilised with an acrylic external fixator assembled from four Kirschner wires of 1.2 $\mathrm{mm}$ in diameter (Mikromed, Dąbrowa Górnicza, Poland) and a double acrylic frame (Dental Spofa, Jicin, Czech Republic). In group 2, stabilisation was achieved with the use of intramedullary Kirschner nails (Mikromed). The fracture and the drilled bone defect were filled with TCP in the form of granulate (Cerasorb; Curasan, Kleinostheim, Germany) mixed with PRP activated with bovine thrombin (Biomed, Lublin, Poland). In the control group, the defect and fracture site were left empty. Fractures in two animals of this group were treated using external fixators and intramedullary nails in the remaining two rabbits. The surgical site was closed layer by layer: fascia and muscles using Dexon 3-0 suture, skin using Ticron 3-0 suture. Postoperative medication included Torbugesic (Pfizer Polska, Warszawa, Poland) for pain relief and Sulphatrim (Scanvet, Warsaw, Poland).

In the first 2 weeks after surgery the animals' body temperature and soft-tissue appearance in the fracture region were monitored. Skin around the bone implant was disinfected. During the healing process, $x$-ray images were taken (day 30 after surgery) and blood was drawn for haematological tests (day 7, 14, 21, 30, 60, and 84 after the surgery).

At 12 weeks from the surgery, the animals were euthanized after premedication with xylazine and ketamine, by intravenous administration of sodium pentothal (Morbital, Biowet Puławy). Bone $\mathrm{x}$-rays were taken and material was collected for graft histological analysis, scanning electron microscopy (SEM) and peripheral quantitative computed tomography (pQCT).

Preparation of the implant material (PRP and TPC). PRP was obtained with the use of a commercially available Curasan doublecentrifugation system (Kleinostheim, Germany). After premedication and local anaesthesia with lignocaine gel (Lignocainum gel 2\%; Polfa, Warsaw, Poland), $8.5 \mathrm{mI}$ of blood was drawn from the auricular vein of each rabbit. The blood was initially centrifuged using an MPV-350 centrifuge $(150 \times g$ for $10 \mathrm{~min})$. The obtained plasma with the so-called buffy coat was aseptically transferred to another test tube and centrifuged again $(400 \times g$ for $15 \mathrm{~min}$ ). The platelet-poor plasma fraction was removed from the tube; after shaking for 20 seconds, the PRP in the lower part of the tube was aseptically transferred to a syringe. The obtained PRP was subsequently activated with bovine thrombin (Biomed Lublin) and mixed with TCP granulate (Cerasorb ${ }^{\circledR} \mathrm{M}$; Curasan) with grain diameter of 500-1000 $\mu \mathrm{m}$ and pore diameter of 5 to $500 \mu \mathrm{m}$.

Radiological examinations. X-Ray images of the operated bones were taken in standard projections postoperatively. Subsequent examinations to monitor the formation of bone union were performed 4 and 12 weeks after the surgery. Images were taken using a mobile rtg Mobilax (Farum, Warsaw, Poland) camera (10 mA, $45 \mathrm{kV}$ ) and Kodak films.

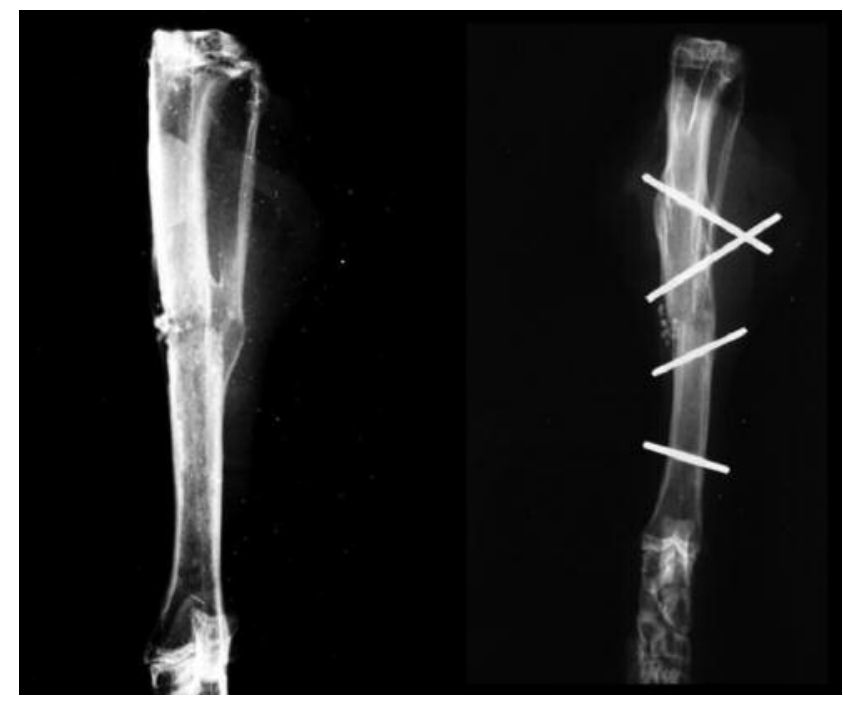

Figure 1. Radiographs 12 weeks after implantation rabbits from both experimental groups showing proper calcified callus in the reconstruction phase.

Peripheral quantitative computed tomography. The tomographic analysis of rabbit bone was conducted using an XCT Research SA Plus pQCT machine (StratecMedizintechnik, GmbH, Pforzheim, Germany) and reference control software (Stratec version 6.20D). The implantation site was located during a preliminary scan, after which each bone was subjected to 20 measurements spaced at $0.25 \mathrm{~mm}$. The examination assessed the volumetric bone mineral density and bone mineral content (BMC) of the samples.

Haematological tests and determination of selected bone profile parameters. In order to conduct basic preoperative haematological tests and obtain initial values for the levels of plasma alkaline phosphatase (ALP), bone alanine phosphatase (BAP) and osteocalcin, 24 hours prior to the planned surgery, $2 \mathrm{ml}$ of blood were drawn from the auricular vein of each rabbit. Blood was subsequently also drawn on days 7, 14, 21, 30, 60, and 84 after the surgery. ALP levels were determined using a Fotometr Pointe Euro biochemical analyser (Pointe Scientific, Canton, MI, USA) The BAP level was determined using ELISA METRA ${ }^{\circledR}$ BAP assay (QUIDEL ${ }^{\circledR}$ Corporation Speciality ProductQuidel Poland, Poznań, Poland) in accordance with the vendor's instructions. The osteocalcin level was determined using ELISA Osteocalcin (BoneGla-Protein, BGP) BioAssay ${ }^{\mathrm{TM}}$ (US Biological, Salem, MA, USA).

Histological examinations. Bone samples containing the entire fracture site area were obtained using a precision saw. These were divided into two halves: one for histological examinations and other for SEM analysis. Histological samples were placed in $10 \%$ buffered formalin, decalcified and stained with haematoxylin and eosin before being examined under a light microscope (NikonEclipse; Nikon, Tokyo, Japan). The process of TCP implantation into the callus after 12 weeks was assessed.

Analysis using SEM. After preparation and removal of soft tissue, a tibial bone fragment containing scar tissue was collected from the 


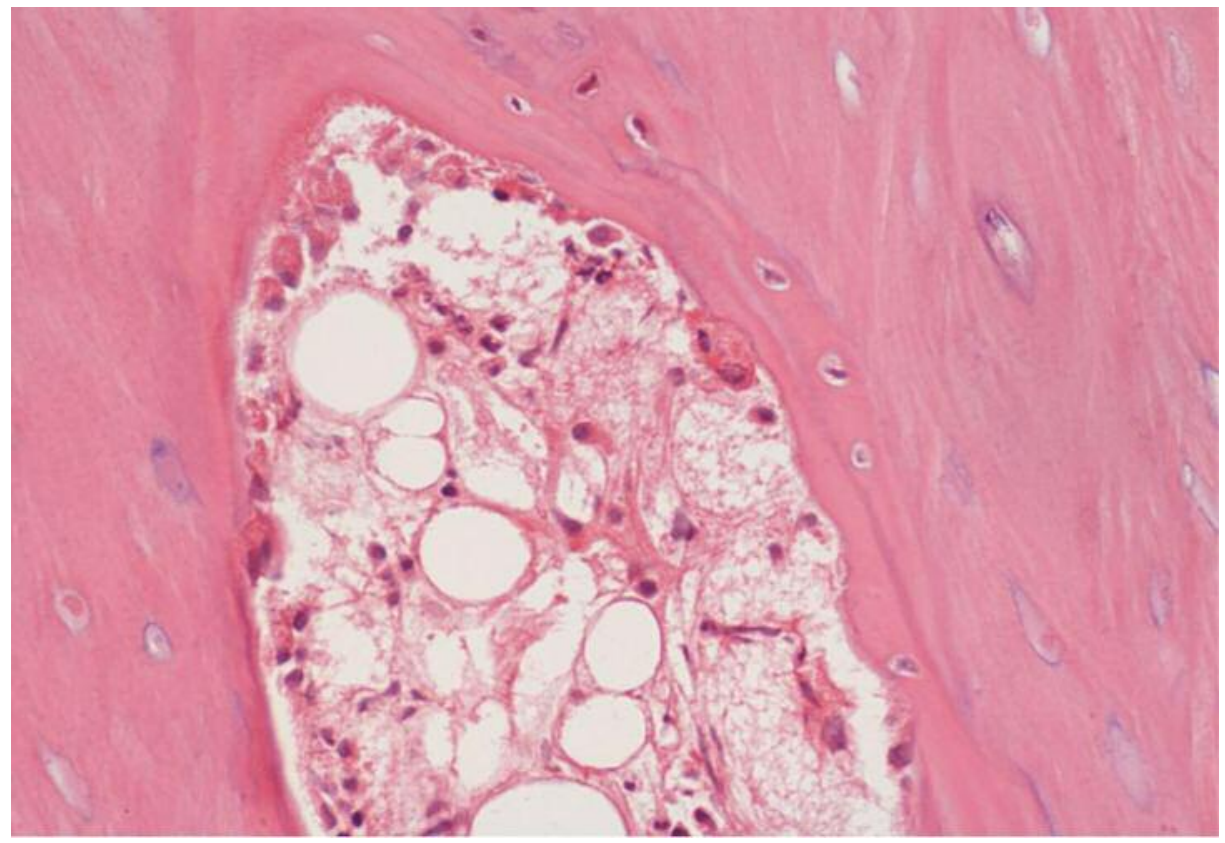

Figure 2. Histological view of an animal from experimental group 1 (external fixator stabilization) 12 weeks after surgery. New bone formation, angiogenesis and the remnant biomaterial are visible. Haematoxylin and eosin staining ( $x 400$ magnification).

fracture site and preserved in $4 \%$ glutaraldehyde, dehydrated using subsequent concentrations of ethyl alcohol and acetone, dried, and gold splattered under vacuum conditions. The obtained specimens were analysed under a Nova Nano SEM Microscope (FEI Company, Tokyo, Japan) to assess the surface of the callus at the fracture site.

Clinical application of the treatment in small animals. Thirty-seven cats and dogs of the Clinic of Veterinary Surgery, University of Life Sciences in Lublin, were included in the study. Animals were treated between 2007 and 2017 for comminuted long-bone fracture and complications thereof, where the therapeutic method entailed the use of PRP and TCP to enhance bone union. Animals were qualified individually, based on the type of fracture (mainly comminuted with bone defect), their age, the extent of soft-tissue trauma and other factors that could hinder the applicability of an autologous bone graft, which is the standard method adopted in our Clinic in the treatment of high-risk fractures. In all the analysed cases, Cerasorb mixed with autologous activated PRP was implanted at the fracture site. The gel was obtained through double centrifugation of blood using a standard dental set by Curasan, in accordance with the aforementioned procedure.

The treatment results observed in the course of the clinical application were assessed on the basis of clinical evaluation and radiological examinations and recorded according to the following scale: Very good result - full recovery, no lameness; good result full bone union, periodic lameness especially after exertion; poor result - no bone union.

Statistical analysis. Data are expressed as the mean \pm standard deviation using Dell ${ }^{\mathrm{TM}}$ Statistica $^{\mathrm{TM}} 13.1$ (StatSoft Poland).

\section{Results}

Experimental study. No complications during the surgery or implantation of the biomaterials were observed in any experimental animals from either group. Ten days after the surgery, the rabbits started to burden the operated limb. In the group of rabbits where external stabilisation was used, two animals showed an inflammatory reaction around the wires, which however subsided after local treatment and had no bearing on the experimental result. After euthanising the animals, bone union was observed macroscopically at the site of the osteotomy. No lesions were observed in the softtissue surrounding the implantation site nor in the regional lymph nodes.

Radiological examination. X-Ray imaging performed 4 weeks after surgery revealed correct bone healing with visible biomaterial at the fracture site. X-Ray imaging after 12 weeks revealed correctly forming bone scar tissue, both in the external stabilisation and the intramedullary nailing groups (Figure 1). In none of the cases was tissue reaction observed at the implantation site.

Histological analysis of bone tissue. The analysed specimens revealed the presence of immature fibrous bone tissue with clearly defined foci of angiogenesis (Figure 2). Overall, various stages of TCP resorption and correct bone union 

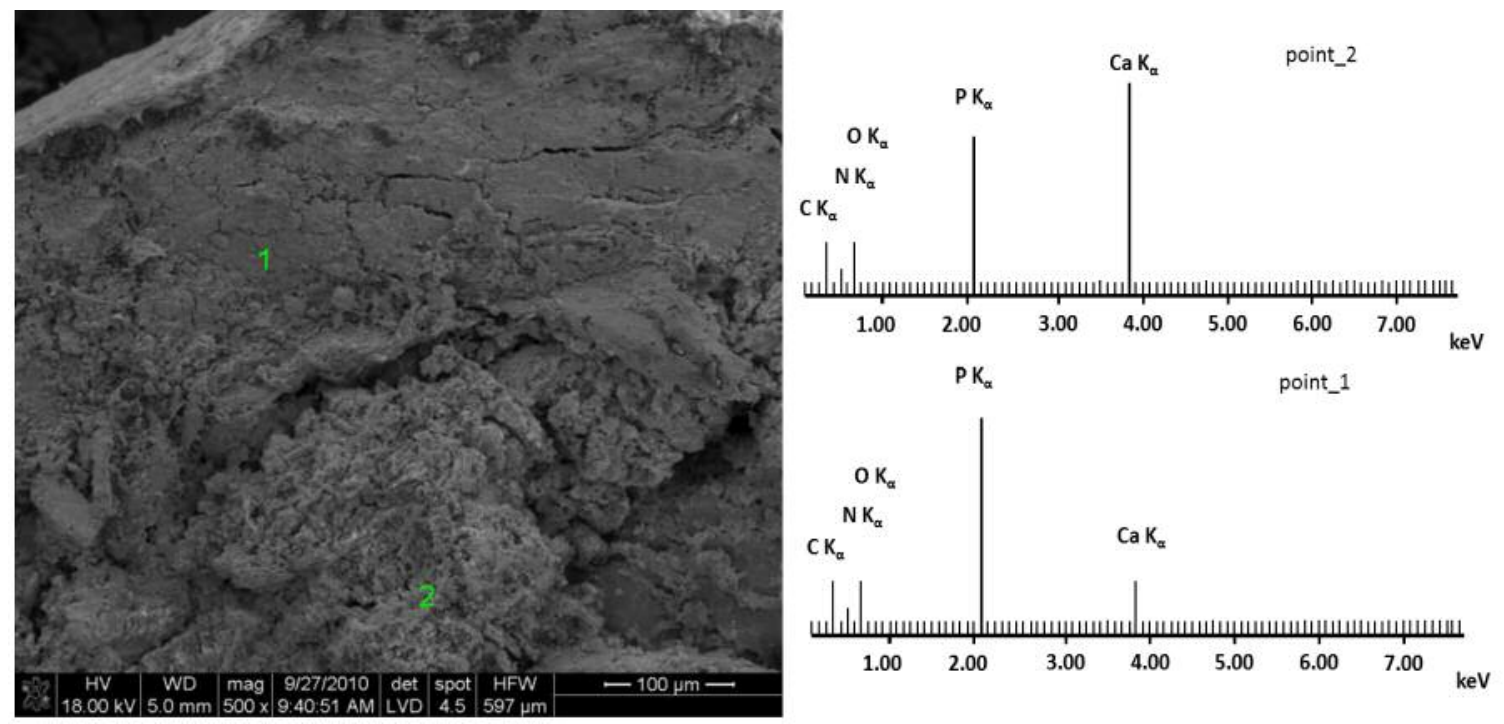

Figure 3. Scanning electron microscopy of experimental group 1 (external fixator stabilization) 12 weeks after surgery. The close adhesion between newly formed callus and $\beta$ tri-calcium phosphate implant is visible (magnification $\times 500$ ).

process were observed, with no significant differences observed between the groups.

SEM. The studied preparations revealed close adhesion between the newly formed callus and the biomaterial. Spot-wise electron-dispersive spectroscopy analyses (Figure 3) indicated both bone tissue areas $(\mathrm{Ca} / \mathrm{P}$ ratio of 1.56$)$ and implant areas $(\mathrm{Ca} / \mathrm{P}$ ratio of 0.36$)$, which confirmed the presence of newly formed tissue in the area of the biomaterial. The images of TCP implantation were identical in both study groups.

Bone turnover markers. The highest level of plasma ALP was observed 14 days after the surgery after having gradually increased in all study groups, with the highest value noted in of group $1(100 \pm 22.67 \mathrm{IU} / 1)$. In subsequent measurements performed 30 and 60 days after the surgery, ALP concentrations had decreased but nonetheless remained above the initial levels.

The conducted tests revealed a statistically significant $(p<0.05)$ increase in the concentration of plasma osteocalcin and BAP 14 days after the surgery in the three analysed groups of rabbits, as compared to initial, pre-operative values. No statistically significant differences were observed between control, group 1 and group 2 within the same time frames. From day 30 onwards, the levels of the markers began to decrease to return to approximately the initial levels on day 60 .

Peripheral quantitative computed tomography. The obtained values of BMC were similar in both study groups within the range of $0.3231-0.7242 \mathrm{~g} / \mathrm{mm}^{3}\left(\right.$ mean $\left.=0.4925 \mathrm{~g} / \mathrm{mm}^{3}\right)$ and were slightly above the values observed in the control group (between 0.3882 and $0.427 \mathrm{~g} / \mathrm{mm}^{3}$, mean $=0.3955 \mathrm{~g} / \mathrm{mm}^{3}$ ). The bone mineral density values were similar in both study groups $\left(\right.$ range $=0.404-0.840 \mathrm{~g} / \mathrm{mm}^{3}$, mean $=0.616 \mathrm{~g} / \mathrm{mm}^{3}$ ) and were slightly higher than the values observed in the control group $\left(\right.$ range $=0.446-0.665$, mean $\left.=0.566 \mathrm{~g} / \mathrm{mm}^{3}\right)$.

Clinical application. During the study period, a total of 37 animals (29 dogs and eight cats) were treated for long-bone fractures with a method involving TCP and PRP used to enhance bone union. The average age of the treated animals was $5 \pm 7.29$ years for dogs (range $=6$ months to 13 years) and $3.8 \pm 3.85$ years for cats (range $=1-12$ years). The mean body mass was $16.7 \pm 12.39 \mathrm{~kg}$ in dogs (range $=1.8-42 \mathrm{~kg}$ ) and $3.9 \pm 0.59 \mathrm{~kg}$ in cats (range $=3-5 \mathrm{~kg}$ ). The fractures involved the diaphysis of the humerus in three cases, radius/ulna in 15 cases, femur in seven cases, and tibia/fibula in 12 cases. All animals underwent surgical treatment, in 12 cases intramedullary nails were used, in 23 cases external stabilisation was applied, and in 2 cases, bone plates were used. The average treatment time was $14.5 \pm 4.49$ weeks (range $=8-24$ weeks).

Overall, full recovery described as a very good result was observed in 23 animals (Figure 4), a good result was achieved in 11 animals (Figure 5), and in three cases, bone union was not observed at the end of the treatment.

\section{Discussion}

Although literature reports extensive research conducted on the resorption of various forms of TCP in experimental 


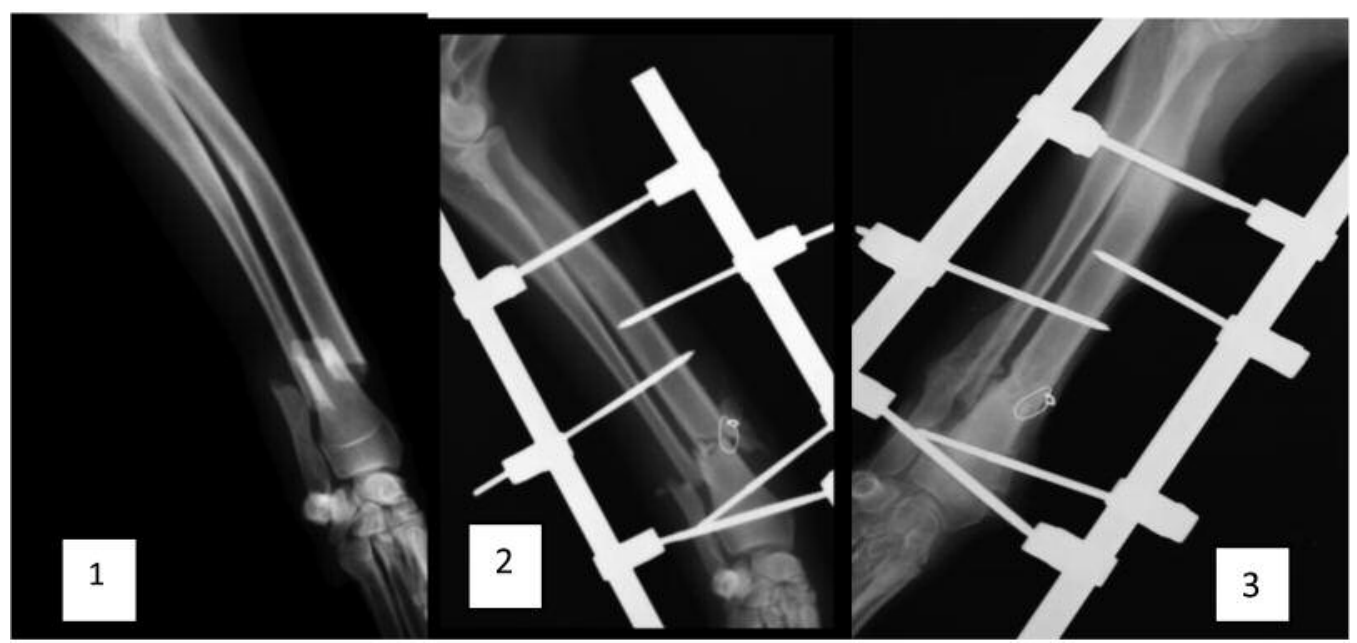

Figure 4. Clinical case: Dog, female crossbred, 4 years old, $25 \mathrm{~kg}$. The fracture of the distal radius (and ulna) 1 day after accident (image 1). After operation: the fracture was surgically fixed by external skeletal fixation and platelet-rich plasma and Cerasorb was applied (image 2). Consolidation time: 12 Weeks, full recovery (scored as very good)-image 3.

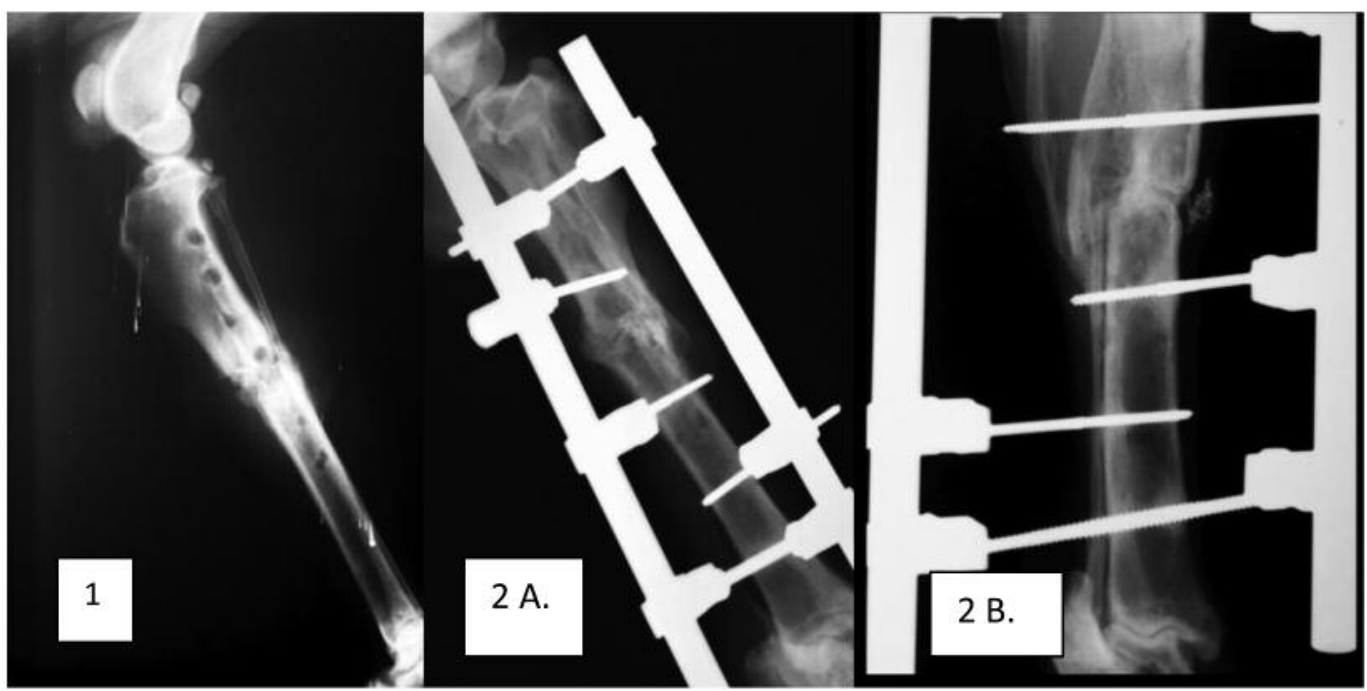

Figure 5. Clinical case: Dog, male German Shepherd, 8 years, $37 \mathrm{~kg}$. The fracture of the tibia, previously treated with acrylic external skeletal fixation, non-union (image 1). Treatment: reoperation, locally platelet-rich plasma and (Cerasorb). Consolidation time: 22 Weeks, clinical result: good (image $2 A$ and $B$ ).

studies (9-16), the number of publications pertaining specifically to the clinical use of this biomaterial in veterinary surgery is very limited $(17,18)$. In the course of our own research, we first developed a research model corresponding to the treatment of comminuted fractures, and then proceeded to apply the same procedure to small animals of our Clinic. The biomaterial used was TCP in the form of granules, $150-500 \mu \mathrm{m}$ in diameter, whose structure corresponded to that of cancellous bone (2), with the addition of activated autologous PRP as the binding agent, facilitating implantation at the site of the fracture and acting as a source of growth factors. The method of obtaining the gel and its exact content have been discussed in our previously published study (19).

Unlike in the case of standard tests of biomaterial biocompatibility at the experimental stage, in this study, the 
material was implanted into the bone defect created in one of the bone fragments as well as into the bone fracture itself. Therefore, biomaterial resorption took place in parallel with the development of bone union, thus reflecting the actual process of healing with the use of metal implants and the biomechanical conditions accompanying the healing process. The period of implantation was equal to the period of bone union formation (12 weeks).

Histopathological analyses focusing on the resorption of TCP enriched with PRP confirmed the formation of healthy bone scar tissue with visible remnants of TCP, which was consistent with results reported by other authors $(14,15,20$, 21), thus confirming that after 12 months, i.e. after the period corresponding to the formation of bone union, the processes occurring at the site of fracture included not only healing and reconstruction of bone but also resorption of the biomaterial.

The close integration between the callus and the biomaterial was confirmed by SEM analyses, which leads to the conclusion that the process of biomaterial resorption has a positive impact on the quality of forming callus $(9,12,15$, $22,23)$. Analyses conducted with the use of pQCT indicated that the density of bone scar tissue formed in the study groups was higher than that in the control, which is consistent with previous studies on the use of TCP in rabbits $(22,23)$. The measurements of the primary bone healing markers did not reveal any statically significant differences between the study groups and the control group, which may be due to the fact that osteotomy was performed in a manner non-traumatic to soft tissues $(24,25)$. However, complete modelling of high-energy trauma is not possible due to humanitarian concerns regarding the treatment of laboratory animals. The obtained results were consistent with others (3, $5,6,18)$ confirming the applicability of PRP in combination with biomaterials in the treatment of bone defects. The experimental study was conducted under conditions corresponding as closely as possible to actual clinical conditions, which further supported the use of this therapeutic method in clinical practice with regard to treatment of fractures in small animals.

During the clinical application of the treatment, bone union was observed in $91 \%$ of the cases, which confirmed the usability of PRP and TCP in surgical treatment of fractures in small animals. Similar results can be obtained with the use of demineralized bone matrix (26) or bone morphogenetic protein (27), however, neither of these materials is readily available, and the cost of such therapy can be a limiting factor for some animal owners. The benefits of TCP were discussed by Franch et al. who suggested the applicability of this biomaterial in veterinary orthopaedics, while also emphasising the fact that the material's character is mainly osteoconductive (2). Other isolated cases of using PRP and TCP in dogs have also been reported (18).
TCP containing activated PRP was used for the treatment of long-bone fractures in 37 small animals of our Clinic of Veterinary Surgery. It is noteworthy that although most of the fractures in question resulted from high-energy trauma with accompanying extensive soft-tissue damage at the site of the fracture, none of the treated animals showed any complications as a result of the implantation and the healing of soft tissues progressed correctly. This suggests beneficial effects of the growth factors contained in PRP, not only with respect to the process of bone union, particularly at its onset, but also with regard to soft tissues surrounding the fracture site. This is consistent with the observations of others reporting the beneficial impact of PRP on the processes of soft-tissue healing (27-30).

In summary, it can be concluded that the use of a combination of TCP and PRP in the treatment of comminuted fractures in small animals may be a valid alternative to the method of cancellous bone grafting. However, due to the relatively small number of animals that were included in the study, continued research is necessary to further monitor the impact of minimally-invasive methods acceptable to both the animals and their owners on the processes of bone union and soft-tissue healing.

\section{References}

1. Ragetly GG and Griffon DJ: The rationale behind novel bone grafting techniques in small animals. Vet Comp Orthop Traumatol 1: 1-7, 2011.

2 Franch J, Diaz-Bertrana MC, Lafuante MP, Fontecha P and Durall I: $\beta$-Tricalcium phosphate as a synthetic cancellous bone graft in veterinary orthopedics. Vet Comp Orthop Traumatol 4: 196-204, 2006.

3 Kanthan Sr, Kavitha G, Addi S, Choon DSK and Kamarul T: Platelet-rich plasma (PRP) enhances bone healing in nonunited critical sized defect: A preliminary study involving rabbit models. Injury Int J Care Injured 42: 782789, 2011.

4 Batista MA, Leivas TP, Rodrigues CJ, Arenas GCF, Belitardo DB and Guarniero R: Comparison between the effects of platelet-rich plasma and bone marrow concentrate on defect consolidation in the rabbit tibia. Clinics 66(10): 1787-1792, 2011.

5 Jungbluth P, Wild M, Grassmann JP, Ar E, Sager M, Herten M, Jager M, Juergen B, Windolf $J$ and Hakimi M: Platelet-rich plasma on calcium phosphate granules promotes metaphyseal bone healing in mini-pigs. J Orthop Res 28: 1448-1455, 2010.

6 Zhang X-L, Wang Y-M, Chu K, Wang Z-H, Liu Y-H, Jilang L$\mathrm{H}$, Chen X, Zhou Z-Y and Yin G: The application of PRP combined with TCP in repairing avascular necrosis of the femoral head after femoral neck fracture in rabbit. Eur Rev Vet Med Pharm Sci 22: 903-909, 2018.

7 Plachokova AS, van den Dolder J, Stoelinga PJ and Jansen JA: The bone-regenerative effect of platelet-rich plasma in combination with an osteoconductive material in rat cranial defects. Clin Oral Impl Res 27: 305-311, 2006.

8 Rabbilard M, Grand J-G, Dalibert E, Fellah B, Gauthier O and Niebauer GW: Effects of autologous platelet-rich plasma gel and calcium phosphate in an ulnar ostectomy model in dogs. Vet Comp Orthop Traumatol 6: 460-466, 2009. 
9 Walsh WR, Vizesi F, Michael D, Auld J, Langdown A, Oliver R, Yu y, Irie $\mathrm{H}$ and Bruce $\mathrm{W}$ : $\beta$-TCP bone graft substitutes in a bilateral rabbit tibial defect model. Biomaterials 29: 266-271, 2008

10 Kondo N, Ogose A, Tokunaga K, Ito T, Arai K, Kudo N, Inoue $\mathrm{H}$ and Endo $\mathrm{N}$ : Bone formation and resorption of highly purified $\beta$-tricalcium phosphate in the rat femoral condyle. Biomaterials 26: 5600-5608, 2005.

11 Nandi SK, Ghosh SK, Kundu B, De DK and Basu D: Evaluation of new porous $\beta$-tri-calcium phosphate ceramic as bone substitute in goat model. Small Rum Res 75: 144-153, 2008.

12 Goel SC, Singh D, Rastogi A, Kumaraswamy V, Gupta A and Sharma N: Role of tricalcium phosphate implant in bridging the large osteoperiosteal gaps in rabbits. Indian J Experiment Biol 51: 375-380, 2013.

13 Field JR, McGee M, Wildenauer C, Kurmis A and Margerrison E: The utilization of a synthetic bone void filler (JAX) in the repair of a femoral segmental defect. Vet Comp Orthop Traumatol 2: 87-95, 2009.

14 Artzi Z, Weinreb M, Givol N, Rohrer M, Nemcowsky M, Prasad $\mathrm{H}$ and Tal $\mathrm{H}$ : Biomaterial resorption rate and healing site morphology of inorganic bovine bone and $\beta$-tricalcium phosphate in the canine: A 24-month longitudinal histologic study and morphometric analysis. Int J Oral Maxillofac Implants 19: 357-368, 2004.

15 Chazano M, Tanaka T, Kitasato S, Kikuchi T and Marumo K: Electron microscopic study on bone formation and bioresorption after implantation of $\beta$-tricalcium phosphate in rabbit model. J Orthop Sci 13: 550-555, 2008.

16 Yilmaz D, Bogan N, Ozkan A, Sencimen M, Ora BE and Mutlu I: Effect of platelet-rich plasma and beta tricalcium phosphate on bone healing. A histological study in pigs. Acta Chirurg Brasil 29: 59-65, 2014.

17 Izumisawa Y, Seno T, Abe R, Miyoshi K, Maehara S, Wakaiki S, Kushiro T, Umar MA, Tsusuki K, Yamashita K and Hayashi S: Axial correction of pes varus by transverse opening wedge osteotomy and T-plate fixation with beta-tricalcium phosphate $(\beta$-TCP) transplantation in Dachsunds. J Vet Med Sci 67: 433440, 2005.

18 Hauschild G, Merten H-A, Bader A, Uhr G, Devick A, MeyerLindenberg and Fehr M: Bioartificial bone grafting: Tarsal joint fusion in a dog using a bioartificial composite bone graft consisting of $\beta$-tricalcium phosphate and platelet-rich plasma A case report. Vet Comp Orthop Traumatol 18: 52-54, 2005.

19 Szponder T, Wessely-Szponder J and Smolira A: Evaluation of platelet-rich plasma and neutrophil antimicrobial extract as two autologous blood-derived agents. Tissue Eng Regen Med 14: 287-296, 2017.
20 Buser D, Hoffmann B, Bernard J-P, Lussi A, Mettler D and Schenk RK: Evaluation of filling materials in membraneprotected bone defects. Clin Oral Impl Res 9: 137-150, 1998.

21 Kovacs K, Velich N, Husznar T, Fenyies B, Suba Z and Szabo G: Histomorphometric and densiometric evolution of the effects of platelet-rich plasma on the remodelling of beta-tricalcium phosphate in Beagle dogs. J Cranofac Surg 16: 150-154, 2005.

22 Park J-W, Kim E-S, Jang J-H, Suh J-Y, Park K-B and Hanawa T: Healing of rabbit calvarial bone defect using biphasic calcium phosphate ceramics made of submicron-sized grains with a hierarchical pore structure. Clin Oral Impl Res 21: 268-276, 2010.

23 Komaki H, Tanaka T, Chazono $\mathrm{M}$ and Kokuchi T: Repair of segmental bone defects in rabbit tibiae using a complex of $\beta$ tricalcium phosphate, type I collagen, and fibroblast growth factor-2. Biomat 27: 5118-5126, 2006.

24 Klein P, Bail HJ, Schell H, Michel R, Amthauer H, Bragulla H and Duda GN: Are bone turnover markers capable of predicting callus consolidation during bone healing? Calcif Tissue Int 75 : 40-49, 2004.

25 Coulibaly MO, Sietsema DL, Burgers TA, Mason J, Williams $\mathrm{AO}$ and Jones CB: Recent advances in the use of serological bone formation markers to monitor callus development and fracture healing. Crit Rev Eukaryot Gene Expr 20(2): 105-127, 2010.

26 Hoffer MJ, Griffon DJ, Schaeffer DJ, Johnson AL and Thomas MW: Clinical application of demineralized bone matrix: A retrospective and case-matched study of seventy-five dogs. Vet Surg 37: 639-647, 2008.

27 Schmoekel HG, Weber FE, Huster K, Schense JG, Rytz U, Spreng D, Schawalder P and Hubbell J: Enhancement of bone healing using non-glycosylated rh-BMP-2 released from a fibrin matrix in dogs and cats. J Small Anim Pract 46: 17-21, 2005.

28 Wang H-F, Gao Y-S, Yuan T, Yu X-W and Zhang C-Q: Chronic calcaneal osteomyelitis associated with soft-tissue defect could be successfully treated with platelet-rich plasma: A case report. Int Wound J 10: 105-109, 2013.

29 Jee C-H, Eom N-Y, Jang H-M, Jung H-W, Choi E-S, Won J-H, Hong I-H, Kang B-T, Jeong DW and Jung D-I: Effect of autologous platelet rich-plasma application on cutaneous wound healing in dogs. J Vet Sci 17(1): 79-87, 2016.

30 Wroblewski AP, Hector BS, Mejia A and Wright VJ: Application of platelet-rich plasma to enhance tissue repair. Oper Tech Orthop 20: 98-105, 2010.

Received August 17, 2018

Revised September 24, 2018

Accepted September 26, 2018 